\title{
Viral hepatitis in resource-limited countries and access to antiviral therapies: current and future challenges
}

\section{Maud Lemoine ${ }^{\star 1}$, Shevanthi Nayagam² \& Mark Thursz²}

'Medical Research Council, The Gambia Unit, Disease Control \& Elimination theme, Liver Unit, Atlantic Road, Fajara, PO Box 273 Banjul, The Gambia

Imperial College London, Department of Hepatology \& Gastroenterology, St Marys, Norfolk Place, London W2 TNY, UK

*Author for correspondence: mlemoine@mrc.gm

Chronic viral hepatitis is a major public health issue worldwide and mostly affects resource-limited countries. These regions combine a considerable set of barriers to containing the epidemic, including shortage of healthcare workers, poor medical infrastructures, insufficient screening and poor access to care and treatment. At a time when morbidity and mortality of chronic liver disease has been widely improved in wealthy countries by new innovative strategies and potent antiviral drugs, it is now urgent to face the challenges of better management of chronic hepatitis in resource-poor countries from the perspectives of global health and social justice.

Chronic viral hepatitis, as well as coinfection with HIV, are major public health problems worldwide. They mostly affect the least-developed countries, which account for $80 \%$ of the world's population and face numerous obstacles in terms of containing the epidemic. This article aims to focus on the burden of chronic hepatitis in resource-limited countries and its current and future challenges in accordance with global equity and social justice.

\section{The burden of chronic viral hepatitis in resource-limited countries}

Approximately 550,000 million people ( $\sim \%$ of the world population) are chronically infected with either hepatitis B virus (HBV; 350-400 million), hepatitis D virus (15 million) and/or hepatitis C virus (HCV; 170-180 million) worldwide $[1,101]$. The most endemic regions have limited resources, with a low human development index and, often, a population living on less than US\$2 a day [102]. HBV and HCV globally account for $60 \%$ of cirrhosis and $80 \%$ of hepatocellular carcinoma (HCC) and cause 1 million deaths each year. These deaths mostly occur in underprivileged regions, which represent $80 \%$ of global deaths related to liver diseases (Figure 1) [1,101,103]. Moreover, HCC, the fifth most common malignancy worldwide, is the third most common cancer in poor countries; and in Africa it is the most common cancer in men and the third most common in women $[2,103]$, affecting young individuals mostly between 30 and 40 years old [3,4].
In low- and middle-income countries, approximately two-thirds of HCCs are attributable to HBV and/or HCV $[5,6]$.

\section{Hepatitis B virus}

The WHO estimates that 2 billion people have been infected with HBV worldwide and approximately 380 million are chronic carriers (6\% of the world population). Approximately 4.5 million new infections are reported globally on an annual basis. HBV is responsible for 620,000 deaths each year [104]. In highly endemic regions, including Africa, the Amazon Basin, and central and southeast Asia, the prevalence of HBV is estimated to be up to $8 \%$, reaching $10-15 \%$ in some countries [7]. In developing regions, HBV infection mostly occurs early in life, with high risk of chronic liver disease. HBV is carried in blood and other body fluids, and is transmitted through mother-to-child (vertical transmission), child-to-child (horizontal transmission) or sexual or parenteral contact. However, routes of transmission differ greatly between regions. Vertical transmission is frequent in Asia, while horizontal transmission from child to child is predominant in Africa [8,9]. As it has been demonstrated that the rate of spontaneous HBV clearance is lower in children, these countries are at high risk of chronic infections with HBV [10]. Up to $90 \%$ of children infected during the first year of life and almost $50 \%$ of those infected between the age of 1 and 5 years will develop chronic hepatitis. In contrast, more than $90 \%$ of acute HBV infection

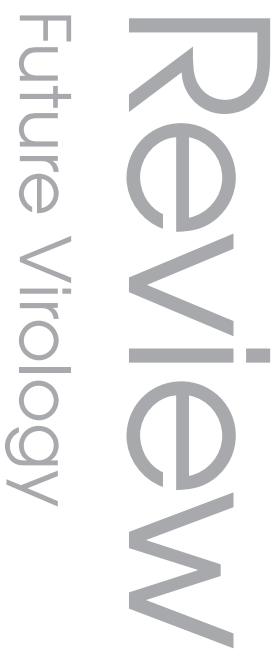

\footnotetext{
Keywords

- DAA $=$ global health $\approx$ HBV

- $\mathrm{HCC}=\mathrm{HCV}=\mathrm{HIV} / \mathrm{AIDS}$

- resource-limited countries

- social justice = treatment

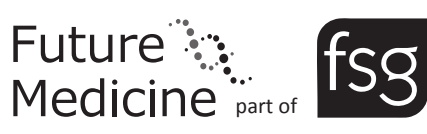




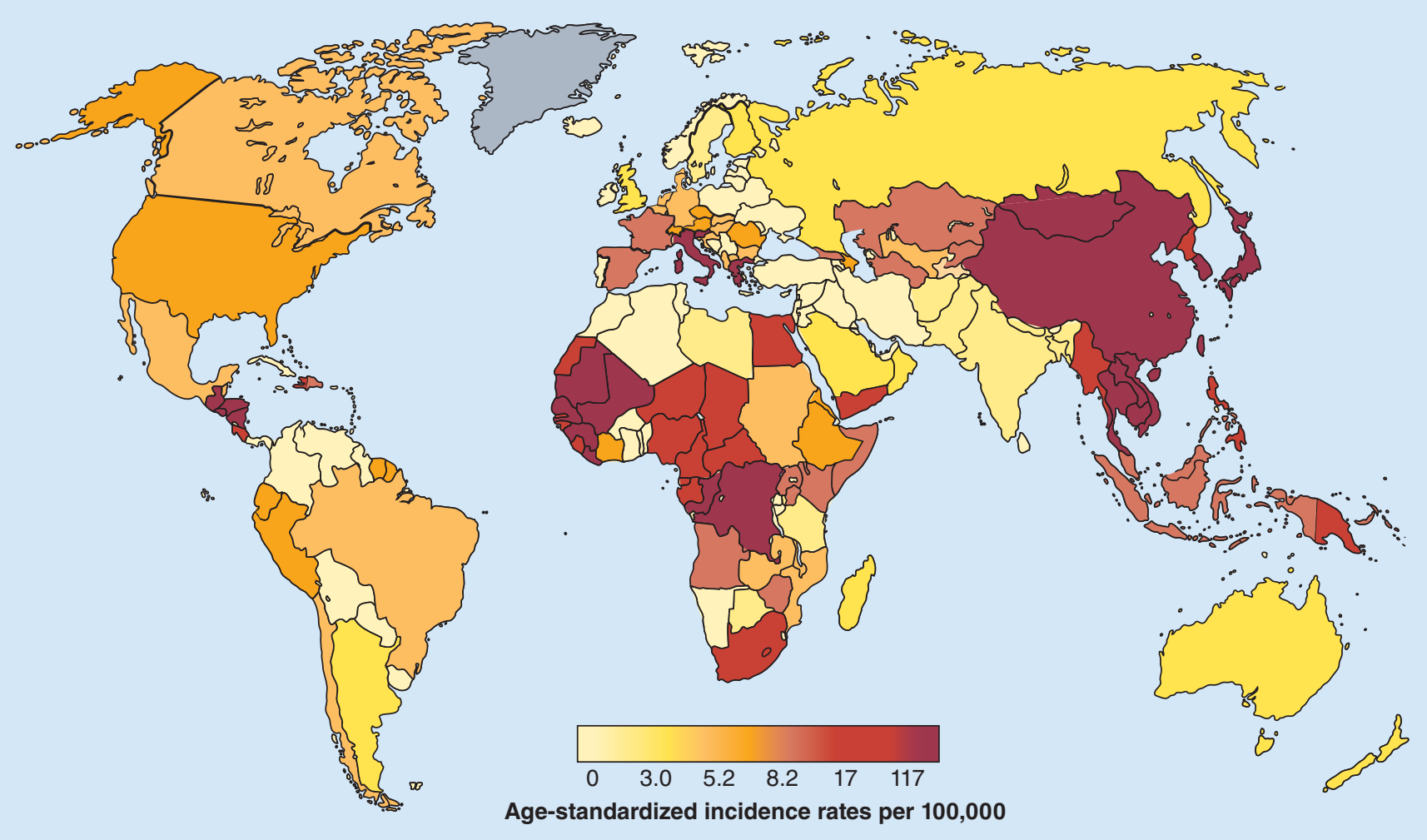

Figure 1. Estimated liver-related mortality incidence in men worldwide.

Reproduced with permission from [103] C GLOBOCAN (2008).

in adults will resolve spontaneously. In addition, it is estimated that $25 \%$ of adults infected during childhood will die prematurely from liver cancer or cirrhosis due to HBV [11]. In HBV-infected individuals, the 5-year cumulative incidence of developing cirrhosis is estimated to be between 8 and $20 \%$, with an annual incidence of HCC of $3-6 \%[12,13]$. Coinfection with HIV and/or hepatitis D virus, sex, viral genotypes (e.g., genotype C) [14], excessive alcohol consumption, or environmental factors (e.g., exposure to mycotoxin aflatoxin) have also been identified as additional factors for fibrosis progression and liver carcinogenesis $[7,15]$.

\section{$\mathrm{HCV}$}

HCV affects approximately 2-3\% of the global population (170-180 million people). Asia and Africa account for 111 million HCV infections, while in the Americas and Europe, approximately 31.5 million people are infected [1]. However, the prevalence estimates among the general population varies considerably between regions and countries (Figure 2), from $1-2 \%$ in west Africa to $4-5 \%$ in central and southeast Asia $[7,16,17]$. These differences are partly due to different patterns of transmission. Parenteral routes are the main mode of HCV transmission. For example, due to the widespread schistosomiasis treatment campaigns of the 1960s in Egypt, this country bears the highest prevalence of HCV in the world, reaching $12 \%$ (i.e., up to tenfold higher than in Western countries) [17]. In Asia, the virus is mostly transmitted through the use of injecting drugs, while in Africa, epidemiological data suggest an important transmission through unsafe medical procedures and injections $[1,17,18]$.

Among at-risk populations (e.g., drug users, $\mathrm{HIV}$-positive individuals and prisoners), HCV prevalence can reach alarming levels, such as $60-80 \%$ in injection drug users and more than $80 \%$ in HIV-coinfected individuals, particularly in Asian countries where the number of injecting drug users is especially high $[1,18]$. The majority of epidemiological studies have been conducted in selected populations that do not reflect national prevalence. Thus, in resourcelimited countries, the lack of national testing and surveillance hampers the collection of accurate data on prevalence among the general population and vulnerable individuals. Infection with HCV accounts for approximately 350,000 annual deaths. Approximately, $70-80 \%$ of acute $\mathrm{HCV}$-infected individuals will develop chronic liver disease and, within 10-30 years, approximately $20 \%$ of them will experience cirrhosis 
and its complications, of which $1-5 \%$ are HCC each year [19].

Cofactors of liver fibrosis progression and HCC have also been identified, including heavy alcohol consumption, HIV coinfection, diabetes, low education and poverty [7].

\section{Coinfection with HIV}

Due to common routes of transmission, viral hepatitis coinfection with HIV is frequent. Out of the 34 million HIV-infected individuals worldwide, $5-25 \%$ are also coinfected with either HBV (2-4 million; 5-20\%) and/or HCV (4-5 million; 5-15\%) [20]. Developing countries face the greatest burden of coinfection. HIV infection has been shown to have a significant impact on the progression of chronic $\mathrm{HBV}$ and $\mathrm{HCV}$, with a higher risk of cirrhosis and HCC [20,21]. In Western countries, coinfection has emerged as a major cause of morbidity and mortality since the introduction of HAART, and the incidence of cirrhosis and its complications, including HCC, has increased greatly over recent years [22]. HCC is now responsible for a quarter of liver-related deaths in HIV patients [23]. Owing to considerable improvements in the management and treatment of HIV/AIDS in resource-limited countries, these regions are likely to face the same alarming mortality rates, with chronic hepatitis becoming a significant clinical problem. However, accurate data on the prevalence, natural history and severity of liver injuries in HIV-infected individuals living in low- and middle-income countries are still deeply lacking [24].

\section{Resource-limited settings maintain the hepatitis epidemic}

In resource-limited settings, the prevalence and mortality rates related to chronic viral hepatitis are the consequence of a combination of factors, including imperfect vaccine coverage (i.e., for HBV), poor education, poverty, inadequate prevention and screening strategies, frequent iatrogenic transmission and, finally, insufficient or even nonexistent access to treatment. In addition, these viruses affect vulnerable and stigmatized populations (e.g., injecting drug users, men who have sex with men, sex workers and prisoners) who are often excluded from the local healthcare systems.

Most countries have elected to vaccinate all children against $\mathrm{HBV}$ through the WHO-sponsored Expanded Program of Immunization. However, vaccine coverage remains low or incomplete, particularly in endemic countries $[5,25]$. In Africa, the

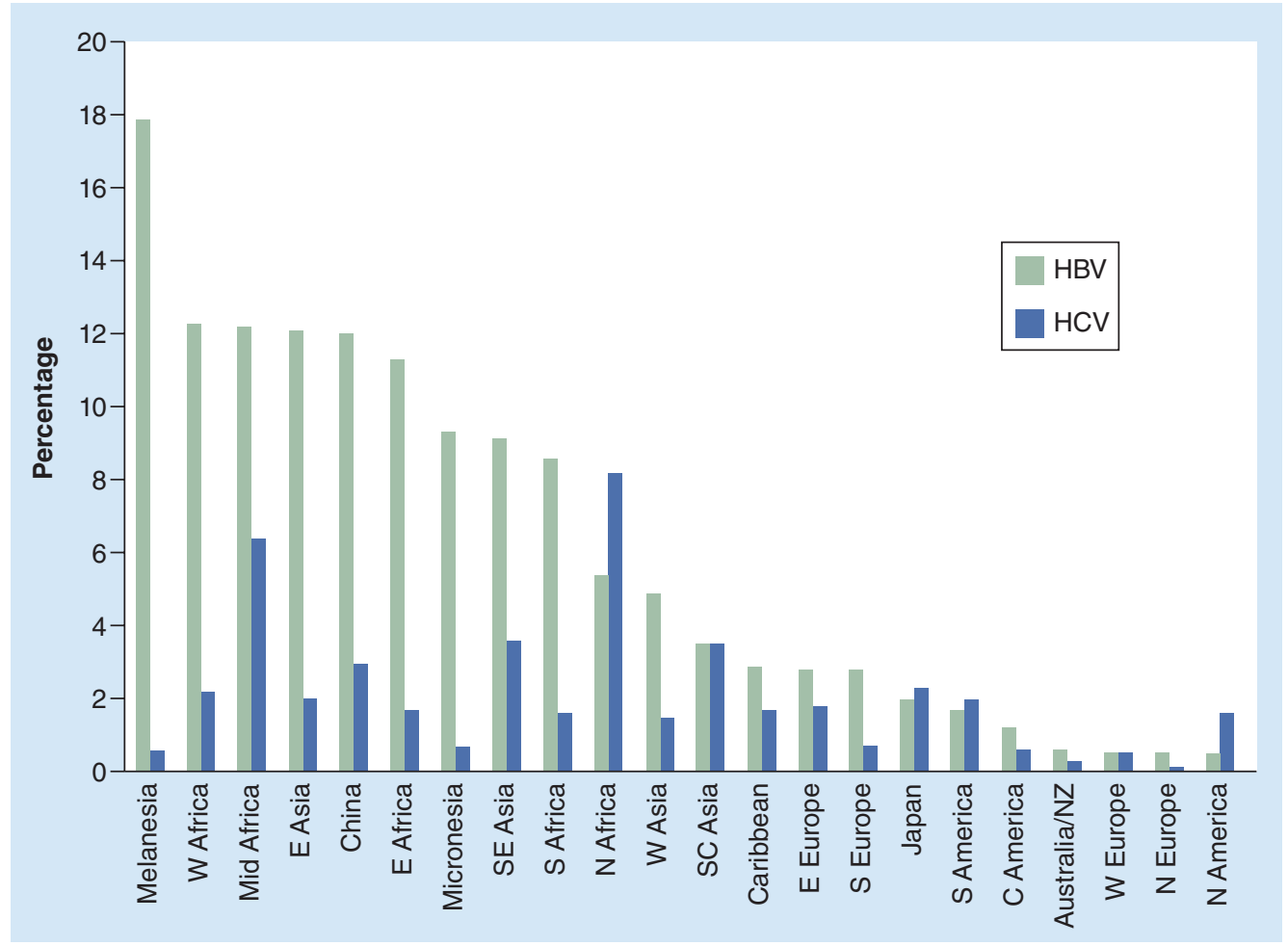

Figure 2. Prevalence of HBsAg carrier and chronic hepatitis C virus status in different geographic regions.

C: Central; E: East; HBV: Hepatitis B virus; HCV: Hepatitis C virus; N: North; NZ: New Zealand; S: South; SC: South central; SE: Southeast; W: West.

Reproduced with permission from [7]. 
vaccine coverage was still below 70\% in 2009, and in southeast Asia it was only $55 \%$ [101]. Despite the overall decrease in $\mathrm{HBsAg}$ prevalence worldwide in young individuals observed since 1990 [26], a recent Taiwanese study confirmed that immunization alone is not sufficient to control the HBV epidemic [27], and additional antiviral prophylaxis in highly viremic pregnant women should be seriously considered [28]. Crucially, vaccination will not benefit patients already chronically infected with $\mathrm{HBV}$, and antiviral therapy forms a strong part of the control of deaths from cirrhosis and HCC [29].

Poverty and illiteracy have been identified as risk factors of viral hepatitis transmission [17]. Poor knowledge of viral hepatitis, even among healthcare workers, also needs to be improved. Several studies reported high rates of $\mathrm{HBV}$ and/or HCV infections among healthcare workers in low- and middle-income countries, with poor awareness and vaccine coverage [30-33]. A high rate of $\mathrm{HBsAg}$ positivity in pregnant women is also common in sub-Saharan Africa as well as southeast Asia. For example, in Nigeria, a recent study reported 8.2\% of HBV infection among 231 pregnant women [34] and in Sierra-Leone, Wurie et al. observed a rate of $6.2 \%$ [35]. Yet, pregnant women are not systematically tested. Moreover, less than $50 \%$ of the blood supply in sub-Saharan Africa is screened for HBV, and according to the WHO, 2-3 million people are infected each year through unsafe injections [36]. Finally, access to treatment is also a major obstacle to containing the epidemic in resource-limited countries.

\section{Poor access to treatment}

Effective treatments for $\mathrm{HBV}$ and $\mathrm{HCV}$ are widely available in resource-rich countries. Viral eradication or control of viral replication have been demonstrated to significantly decrease the risk of cirrhosis and its complications, including HCC [37,38], and even to induce regression of fibrosis and cirrhosis [39]. Treatment for hepatitis B has been considerably improved by the advent of potent nucleos(t)ide analogs (tenofovir and entecavir) with high barriers to resistance and new highly effective direct-acting antiviral drugs (DAAs) against $\mathrm{HCV}$, which are paving the way to widely reducing the morbidity and mortality of the disease in wealthy regions. By contrast, in developing countries with high endemicity, access to hepatitis antiviral therapy is still very limited.

\section{HBV antiviral therapy}

In resource-limited countries, tenofovir, a potent and well-tolerated antiviral drug with dual activity against $\mathrm{HBV}$ and $\mathrm{HIV}$, is available at generic prices ( $€ 72 /$ patient/year), but it is still restricted to HIV-infected individuals. This drug must be used to treat HBV-mono as well as coinfected persons without discrimination against non-HIV-infected individuals. In many countries, the widespread use of the first-generation HBV drugs, lamivudine and adefovir, rather than tenofovir or entecavir as first-line treatments of HBV, has led to a worrying burden of patients with drug resistance [40].

In HIV individuals, HBV coinfection is now an indication for starting immediate HAART when HBV treatment is required and/or CD4 levels are $<500 / \mathrm{mm}^{3}$ [41]. Although WHO recommends tenofovir as a first-line option, particularly for HIV/HBV-coinfected patients, only $8 \%$ of HIV-infected individuals received a therapy regimen with tenofovir in developing countries in 2009 [105]; and in Africa, only three countries (Lesotho, Namibia and Zambia) adopted tenofovir as a first-line regimen in national guidelines in 2009 [42]. However, a recent WHO survey observed improvement, as $24.3 \%$ of adults on antiretroviral treatment (ART) in low- and middle-income countries are now on first-line tenofovir disoproxil fumaratebased regimen. [Ford N, Pers. Comm.], but the number of countries remains limited. A few studies have analyzed the prevalence of $\mathrm{HBV}$ resistance to lamivudine (3TC) in HIV/HBV-coinfected patients in sub-Saharan Africa; in The Gambia, a study found $15 \%$ resistance to 3 TC in a small cohort of $21 \mathrm{HIV} / \mathrm{HBV}$-coinfected individuals [43], and an estimated incidence of $7.5 \%$ was reported in Kenya [44]. Such drug resistance is associated with uncontrolled viral replication that is now well-documented as a factor of progression to cirrhosis and HCC, and the current international guidelines recommend the use of second-generation drugs (tenofovir or entecavir) for the treatment of $\mathrm{HBV}$-monoinfected patients in order to achieve complete control of HBV replication [12].

\section{HCV antiviral therapy}

Pegylated interferon therapy (PegIFN)-ribavirin (RBV) combined therapy is still the standard of care for the majority of HCV-infected patients worldwide. For individuals infected with $\mathrm{HCV}$ genotype 1, new DAAs may become the standard of care in the majority of resource-rich countries in the near future. These new molecules (telaprevir and boceprevir) are able to achieve a higher rate of sustained virologic response of approximately $75 \%$ and even more for the 
second generation of DAAs under investigation [45]. However, the high costs and the pharmaceutical patents of these drugs, which also require a regular specific follow-up, make HCV treatments poorly accessible in low- and middleincome countries. Biosimilar PegIFN have been developed and commercialized at lower prices such as in Egypt (Reiferon Retard $\left.{ }^{\circledR}\right)$, but without randomized trials and comparison with the other validated PegIFN molecules. PegIFN-RBV treatment still costs approximately $€ 15,000$ 25,000 for a 48-week course in Europe, without taking into account the additional biological and medical costs. DAAs are even more expensive $(\sim € 20,000-40,000$ per year for telaprevir and boceprevir). To date, new IFN-free oral drug regimens are under investigation. They may substantially improve the rate of sustained virologic response, as well as reducing treatment complexity and side effects. These molecules may also provide promising results in HIV-infected individuals. The simplicity and efficiency of such new drugs may be adapted to resource-limited settings and their access should be considered in such countries in the future.

In addition, a recent meta-analysis included 93 studies from low- and middle-income countries, and showed that the success rate of HCV treatment in patients living in resource-limited settings is similar to the rate reported in patients from wealthy countries [46]. Finally, a modeling case study performed in Vietnam has recently proposed that the treatment for hepatitis $\mathrm{C}$ is prevention of transmission [47]. However, IFNbased therapy requires strong medical, psychological and social support, which is very difficult to deliver in resource-constrained settings. Thus, IFN-sparing regimens should facilitate the ability to deliver better-tolerated and more efficient $\mathrm{HCV}$ treatments in these settings.

Thus, in the absence of efficient $\mathrm{HCV}$ vaccine and from a perspective of the global eradication of HCV, access to new HCV therapies must be seriously considered. Of course, clinical trials adapted to the local resource-poor settings and cost-effectiveness studies are urgently needed in this setting to demonstrate the feasibility and benefits of $\mathrm{HCV}$ antiviral therapy.

The high cost of antiviral therapies is not the only limiting factor of access to treatment. The lack of medical infrastructure and laboratories, combined with the dramatic shortage of healthcare workers and diagnostic tools, are additional obstacles in developing efficient access to treatment for chronic hepatitis. The challenge is complex and not limited to decreasing drug prices.

\section{Challenging the burden}

Given the alarming data on chronic hepatitis in poor countries and the availability of efficient drugs in wealthy countries, access to treatment for viral hepatitis in resource-limited countries must be urgently improved. This is not only a question of global health, but also a question of equity and social justice. As has been shown with the HIV/AIDS epidemic, such a challenge requires essential conditions, including: a reinforcement of global and national political will; a substantial decrease of drug prices; a strengthening of medical infrastructures and human resources; improved awareness, education and screening; and a demonstration that delivering antiviral therapies is safe, efficient and feasible in a resource-poor setting.

\section{Social justice confronting market logic}

The highest attainable standard of health has been recognized as a fundamental human right since 1946 by several national constitutions, including the WHO constitution, asserting that 'state parties will take appropriate steps to ensure the realisation of this right, recognising to this effect the essential importance of international cooperation'. Such a statement confers on states and supranational institutions an obligation to avoid preventable deaths. This obligation should be based on Kant's universal principle or categorical imperative, stating that 'any action is right if it can coexist with everyone's freedom in accordance with a universal law'. And, as argued by the Nobel Economics Laureate, Armatya Sen, everyone's freedom is secured by providing capabilities for all; for example, material tools to ensure the fundamental rights, including access to health. Economics must be a moral science and freedom is a fundamental condition of global justice [48].

From this perspective, scientific and medical knowledge for ensuring access to health for all becomes a common good for humankind. As a result, science and medicine cannot be exclusively based on either market logic or a utilitarian doctrine that accepts the sacrifice of a part of the population in the name of the welfare of a majority. Political choices cannot be fair and legitimate if they are in contradiction with essential human rights.

Yet, since 1995, drug production has been regulated by the Trade-Related Aspects of Intellectual Property Rights agreements administered by the World Trade Organization. These agreements mean that all countries, whatever their level of development, must comply with 20 -year patent protection for pharmaceutical products in order to remain World Trade Organization members and 
to be able to access the global market. As a result, countries cannot produce generic versions of a drug until after 20 years, conferring the patent holder a strong monopoly on the drug, and the highest price that the market can bear. This greatly limits the affordability and availability of many drugs, including essential medications, leading to millions of avoidable deaths. Although three decades ago, over $25 \%$ of the world's pharmaceuticals were produced in developing and middle-income countries, today the developed world hold the global pharmaceutical market and consume more than $90 \%$ of all pharmaceutical products [49]. Pharmaceutical companies defend product patents as a necessary incentive for investments in research and development. However, scientific research remains inequitable, as $90 \%$ of investments for research and development still focus on the richest $10 \%$ of the world population. In 2004, out of $\$ 70$ billion invested in new drugs, only $0.001 \%$ was dedicated for diseases in resource-poor countries [50]. Moreover, recent surveys suggest that one out of two novel medicines provide nothing new from a therapeutic perspective. According to the National Institute for Health Care and Management, in 2002 an analysis of more than 1000 new drugs approved by the US FDA found that three-quarters had no therapeutic benefit over pre-existing products [51].

In 2001, strong pressure from nongovernmental organizations and civil society led to the Doha declaration on Trade-Related Aspects of Intellectual Property Rights and public health, allowing compulsory licenses for some essential medicines 'to protect public health and promote access to medicines for all'.

Pharmaceutical firms are far from being the only responsible party for such inequity. Governments and international organizations also have a significant responsibility regarding the choice of their priorities and expenses. When worldwide military expenditure has increased by $49 \%$ from 2000 to 2009, totaling an estimated $\$ 1531$ billion, according to the Stockholm International Peace Research Institute, it is difficult to accept that higher financial investments cannot be achieved for health in resource-poor countries.

The current economic and commercial logic largely contributes to inequitable access to health, excluding the most underprivileged population and thus violating international health obligations.

Moreover, social justice is a moral virtue essential to each political institution and is even 'the first virtue of social institutions, as truth is of systems of thought. A theory, however elegant and economical, must be rejected or revised if it is untrue; likewise, laws and institutions, no matter how efficient and well-arranged, must be reformed or abolished if they are unjust. Each person possesses an inviolability founded on justice that even the welfare of society as a whole cannot override. For this reason justice denies that a loss of freedom for some is made right by a greater good shared by others' [52]. From a Rawlsian perspective, social and economic inequities are acceptable if 'they are to be of the greatest benefit of the least-advantaged members of society' [52]. Today, health statistics in resource-poor countries demonstrate that we are far from being in harmony with this concept of social fairness.

Thus, it is time that the current political institutions reaffirm a position more in favor of their populations than their own financial interests. In terms of intellectual property, new approaches have been proposed to ensure better access to medicines in resource-limited countries. For example, the creation of a medicines patent pool, which aims at pharmaceutical companies that can register their products in a common health impact fund and sell the drugs at lower prices in resource-poor countries. The fund proposes to assess the impact on population health and provide incentives to firms in exchange [106]. Finally, tenofovir, an efficient and well-tolerated treatment for chronic viral hepatitis B can be delivered in developing countries at generic prices. However, currently, low-price tenofovir is only available for HIV-infected patients, mostly through the Global Fund; thus, not being HIV- positive is ironically a disadvantage. It is time that international agencies, including the Global Fund, pay attention to this discriminating access to treatment in resource-poor countries.

Regarding the burden of hepatitis, changes have been emerging. Over the last 2 years, policy-makers have expressed stronger interests and political willingness to fight viral hepatitis. In 2010, the World Health Assembly adopted a resolution calling for interventions for the prevention and control of viral hepatitis [107]. In 2011, west African countries also called for better care and treatment of viral hepatitis in poor countries [108]. A recent study, performed in collaboration with World Alliance Hepatitis and the WHO, reported a need for national programs and policies for viral hepatitis in resource-limited countries [24]. Finally, the WHO Global Hepatitis Program recently underlined the importance of documenting the severity of chronic viral hepatitis and setting up local guidelines [24]. WHO guidelines are also urgently needed for the management of viral hepatitis adapted to the local settings. However, 
concrete actions must also now be implemented, following the considerable battle deployed against HIV/AIDS epidemic.

\section{Lessons from HIV/AIDS}

History repeats itself, as the obstacles to viral hepatitis therapies are similar to those faced 10 years ago with the HIVIAIDS epidemic: the high cost of drugs and the pharmaceutical patents; the perceptions of policy-makers regarding the complexity and the side-effects of the treatment, the lack of medical and laboratory facilities combined with the shortage of trained doctors and nurses; and the insufficient political will from international policy-makers, donors and local governments. However, the HIV/AIDS epidemic has demonstrated that such obstacles can be overcome, and lessons from HIV/AIDS must be applied to fighting viral hepatitis. Until the mid-2000s, ART cost more than $\$ 10,000$ per patient per year, and treatment was not considered cost-effective [53]. Some policy-makers could even argue that 'many people in Africa have never seen a clock or a watch their entire lives. If you say $1 \mathrm{pm}$. in the afternoon, they do not know what you are talking about' [54]. Until 2002, the WHO refused to include ART on the list of essential medication [54]. Today, following the strong pressure on policy-makers and drug companies by civil society, this cost has fallen to less than $\$ 100$ per person per year. As a result, the number of individuals receiving ART in developing countries has increased considerably from 200,000 in 2000 to 8 million to date. Only $0.1 \%$ of African individuals with HIV received ART in 2000, compared with 54\% in 2011 [109]. Thus, the HIV/AIDS epidemic has demonstrated that pharmaceutical support can be obtained and patents can be waived in cases of severe public health risk.

In practice, the human and infrastructure capacities that have been deployed to fight the HIV/AIDS epidemic should be used to provide care and treatment to patients suffering from viral hepatitis, given that there is an obvious overlap between HIV and viral hepatitis epidemics, and the management of HIV and viral hepatitis share strong similarities. However, caution is needed and lessons must be learned from previous vertical programs targeting specific disease. Although these programs (e.g., The Global Alliance for Vaccines and Immunisation, Global Fund.) have proven to be effective at obtaining results in the control of specific epidemics, they have also tended to marginalize other public health issues, such as noncommunicable diseases, which is a serious killer in low- and middle-income countries. As a consequence, each vertical program should have a strong parallel horizontal approach to reinforce local administrative, training and medical infrastructures and thereby increase the effectiveness of the interventions. In terms of funding, the international health community should consider the importance of setting up a sustained Global Fund for Health based on innovating funding (e.g., involving the private sectors and the pharmaceutical companies) that integrates vertical interventions targeting specific public health issues. African states must also take more responsibility for healthcare funding, comply more fully with the Abuja declaration, and increase their commitment to building national health insurance systems - a solution that has produced interesting results in Rwanda [55,56].

HIV/AIDS programs should now implement programs on viral hepatitis using the capacity deployed to fight HIV/AIDS. Moreover, the Global Fund that provides tenofovir at generic prices for HIV-infected patients should now open access to HBV-monoinfected individuals in poor countries. One of the biggest challenges is obviously the urgent requirement to identify the most severe cases requiring treatment. Thus, transfer of knowledge, capacities and diagnostic tools are crucial steps to improving the response to the epidemic of viral hepatitis in poor countries.

\section{Transfer innovation \& knowledge to resource-poor countries}

Beyond the advent of new potent antiviral medications and the necessity to reduce their prices, new innovative tools have also dramatically improved the management of viral hepatitisinfected patients in resource-rich countries, and should be considerably helpful for the management of chronic hepatitis in resource-poor settings.

Screening the population for viral hepatitis may be easily done at low cost using point-of-care tests and dried-blood-spot testing, the samples for which can be stored at ambient temperature and provide important virological data (genotype and viral load) [57]. Point-of-care tests for rapid genotype and viral load assessment are also under development. Hepatic assessment can be performed using portable ultrasonography and transient elastography (Fibroscan ${ }^{\circledR}$, Paris, France) or other noninvasive markers of inflammation and fibrosis to select and follow-up the most severely infected patients.

All of these new technologies should help provide accurate data on the proportion of patients with severe chronic liver disease, and in designing 
access programs and therapeutic strategies adapted to the local resource-poor settings using infrastructure and human resources that have been deployed to fight the HIV/AIDS epidemic in resource-poor countries. In addition, knowledge on viral hepatitis and its management should be improved. The number of liver specialists in poor countries is very limited. Thus, efforts to increase expertise capacity are necessary, and programs on viral hepatitis will have to incorporate systematic training and capacity building.

In conclusion, the burden of chronic hepatitis mostly affects resource-limited countries. Access to screening, care and treatment has become an urgent consideration, not only for global health, but also for social justice and equity issues.

The international health community now has not only the legitimacy, but also the capacity and the possibility to face this challenge. The scientific and medical community is not only bound to the creation of the possible, but also to the confrontation of what is believed to be impossible, keeping in mind that science without politics has no impact, and politics without science can be dangerous; without programs, however, people do not benefit [54]. Lessons must be drawn from the HIV/AIDS epidemic. Challenging viral hepatitis in resource-poor countries is complex but can be achieved with the combined efforts of the international health community, governments, civil society and pharmaceutical companies.

\section{Future perspective}

Fighting the viral hepatitis epidemic and its consequences in resource-limited countries is challenging but essential. Screening and access to antiviral therapy represent strong elements in the strategy for reduction of deaths from cirrhosis and HCC worldwide. Indeed, despite improved HBV vaccination coverage, patients already chronically infected with the virus will not benefit from immunization programs. Thus, screening and assessing the severity of liver disease is crucial in order to select patients eligible for treatment. Moreover, in the absence of an HCV vaccine and considering the advent of potent antiviral drugs in the near future, access to HCV therapies, particularly new IFN-free regimens, must be seriously considered for patients living in resource-limited settings.

Taking a global health and social justice perspective, the improvements that have been achieved in wealthy countries in the management of viral hepatitis must also benefit patients living in resource-poor (often the most endemic) countries.

It is the responsibility of health policy-makers, medical doctors, scientists and governments to improve access to screening, care and treatment for viral hepatitis. The implementation of clinical trials and national programs adapted to the local conditions of resource-poor settings, and the carrying out of cost-effectiveness studies are urgently needed to demonstrate the feasibility, safety and benefits of such interventions in the future.

\section{Executive summary}

\section{The burden of chronic viral hepatitis}

- In total, 550,000 million people are chronically infected with hepatitis B virus (HBV; 350-400 million), hepatitis D (15 million) and/or hepatitis C virus (170-180 000 million).

- HBV and hepatitis C virus account for $60 \%$ of cirrhosis, $80 \%$ of hepatocellular carcinoma and 1 million deaths each year.

- The burden of chronic hepatitis mostly affects resource-limited countries.

\section{Challenging the burden}

- HBV vaccination coverage must be improved.

- Awareness, education, training and screening are needed.

- A better global and national political is required.

- National and WHO guidelines should be designed.

- Programs should be implemented to demonstrate the feasibility and safety of antiviral therapy in a resource-poor setting.

- Drug prices should be substantially decreased, taking a global health and social justice perspective.

- Tenofovir should be provided to HIV- and non-HIV-infected individuals with the support of international health agencies, local governments and donors.

- Medical infrastructures should be strengthened.

- The human and infrastructure capacities that have been deployed to fight HIV/AIDS should be used to fight viral hepatitis epidemic.

\section{Future perspective}

- HBV vaccination will not benefit patients already chronically infected with hepatitis B.

- Screening, assessing cases and providing access to HBV is an urgent priority in the future.

- Access to new direct-acting antivirals for hepatitis C in low- and middle-income countries should be seriously considered.

- Programs and trials on viral hepatitis must be implemented in resource-limited settings. 


\section{Acknowledgements}

The authors would like to thank D Saadoun, Professor of Philosophy and Senior Lecturer in Political Science, for his interest and precious comments on social justice and health equity.

\section{Financial \& competing interests disclosure}

$S$ Nayagam is a Wellcome Trust/Imperial College London clinical research fellow. Her work is funded by the Wellcome Trust (grant $097816 / Z / 11 / Z$ ). The authors have no other relevant affiliations or financial involvement with any organization or entity with a financial interest in or financial conflict with the subject matter or materials discussed in the manuscript apart from those disclosed.

No writing assistance was utilized in the production of this manuscript.

\section{References}

1. Lavanchy D. Evolving epidemiology of hepatitis C virus. Clin. Microbiol. Infect. 17, 107-115 (2011).

2. Ferlay J, Shin HR, Bray F, Forman D, Mathers C, Parkin, DM. Estimates of worldwide burden of cancer in 2008: GLOBOCAN 2008. Int. J. Cancer (2010).

3. Kirk GD, Lesi OA, Mendy M et al. The Gambia Liver Cancer Study: infection with hepatitis $\mathrm{B}$ and $\mathrm{C}$ and the risk of hepatocellular carcinoma in west Africa. Hepatology 39(1), 211-219 (2004).

4. Tsukuma H, Hiyama T, Tanaka S et al. Risk factors for hepatocellular carcinoma among patients with chronic liver disease. N. Engl. J. Med. 328, 1797-1801 (1993).

5. Jemal A, Bray F, Forman D et al. Cancer burden in Africa and opportunities for prevention. Cancer 118(18), 4372-4384 (2012).

6. de Martel C, Ferlay J, Franceschi S et al. Global burden of cancers attributable to infections in 2008: a review and synthetic analysis. Lancet Oncol. 13, 607-615 (2012).

7. El-Serag HB. Epidemiology of viral hepatitis and hepatocellular carcinoma. Gastroenterology 142, 1264-1273 (2012).

8. Stevens CE, Beasley RP, Tsui J, Lee WC. Vertical transmission of hepatitis $\mathrm{B}$ antigen in Taiwan. N. Engl. J. Med. 292, 771-774 (1975).

9. Whittle HC, Bradley AK, McLauchlan K et al. Hepatitis B virus infection in two Gambian villages. Lancet 1, 1203-1206 (1983).

10. Edmunds WJ, Medley GF, Nokes DJ, Hall AJ, Whittle HC. The influence of age on the development of the hepatitis B carrier state. Proc. Biol. Sci. 253, 197-201 (1993).
11. Goldstein ST, Zhou F, Hadler SC et al. A mathematical model to estimate global hepatitis B disease burden and vaccination impact. Int. J. Epidemiol. 34, 1329-1339 (2005).

12. European Association for the Study of the Liver. Clinical practice guidelines: management of chronic hepatitis B virus infection. J. Hepatol. 57, 167-185 (2012).

13. Lin X, Robinson NJ, Thursz M et al. Chronic hepatitis B virus infection in the Asia-Pacific region and Africa: review of disease progression. J Gastroenterol. Hepatol. 20, 833-843 (2005).

14. Yang HI, Yeh SH, Chen PJ et al. Associations between hepatitis $\mathrm{B}$ virus genotype and mutants and the risk of hepatocellular carcinoma. J. Natl Cancer Inst. 100, 1134-1143 (2008).

15. El-Serag HB. Hepatocellular carcinoma. N. Engl. J. Med. 365, 1118-1127 (2011).

16. Ocama P, Seremba E. Management of HIV and hepatitis $\mathrm{C}$ virus infections in resourcelimited settings. Curr. Opin. HIV AIDS6, 539-545 (2011).

17. Paez Jimenez A, Mohamed MK, Eldin NS et al. Injection drug use is a risk factor for HCV infection in urban Egypt. PLoS ONE 4, e7193 (2009).

18. Nelson PK, Mathers BM, Cowie B et al. Global epidemiology of hepatitis B and hepatitis $\mathrm{C}$ in people who inject drugs: results of systematic reviews. Lancet 378, 571-583 (2011).

19. Alazawi W, Cunningham M, Dearden J, Foster GR. Systematic review: outcome of compensated cirrhosis due to chronic hepatitis C infection. Aliment. Pharmacol. Ther. 32, 344-355 (2010).

20. Hoffmann CJ, Thio CL. Clinical implications of HIV and hepatitis B co-infection in Asia and Africa. Lancet Infect. Dis. 7, 402-409 (2007).

21. Lacombe K, Rockstroh J. HIV and viral hepatitis coinfections: advances and challenges. Gut 61 (Suppl. 1), i47-i58 (2012).

22. Joshi D, O'Grady J, Dieterich D, Gazzard B, Agarwal K. Increasing burden of liver disease in patients with HIV infection. Lancet 377 , 1198-1209 (2011).

23. Salmon-Ceron D, Rosenthal E, Lewden C et al. Emerging role of hepatocellular carcinoma among liver-related causes of deaths in HIV-infected patients: the French national Mortalite 2005 study. J. Hepatol. 50, 736-745 (2009).

24. Easterbrook P, Sands A, Harmanci H. Challenges and priorities in the management of $\mathrm{HIV} / \mathrm{HBV}$ and $\mathrm{HIV} / \mathrm{HCV}$ coinfection in resource-limited settings. Semin. Liver Dis. 32, 147-157 (2012).

25. Zanetti AR, Van Damme P, Shouval D. The global impact of vaccination against hepatitis B: a historical overview. Vaccine 26, 6266-6273 (2008).

26. Ott JJ, Stevens GA, Groeger J, Wiersma ST. Global epidemiology of hepatitis B virus infection: new estimates of age-specific HBsAg seroprevalence and endemicity. Vaccine 30, 2212-2219 (2012).

27. Chen HL, Lin LH, Hu FC et al. Effects of maternal screening and universal immunization to prevent mother-to-infant transmission of HBV. Gastroenterology 142, 773-781 (2012).

28. Dusheiko G. Interruption of mother-to-infant transmission of hepatitis B: time to include selective antiviral prophylaxis? Lancet 379 , 2019-2021 (2012).

29. Thursz M, Njie R, Lemoine M. Hepatitis: Global eradication of hepatitis B-feasible or fallacy? Nat. Rev. Gastroenterol. Hepatol. 9, 492-494 (2012).

30. Adebamowo CA, Ajuwon A. The immunization status and level of knowledge about hepatitis B virus infection among Nigerian surgeons. West Afr. J. Med. 16, 93-96 (1997).

31. Sukriti, Pati NT, Sethi A et al. Low levels of awareness, vaccine coverage, and the need for boosters among health care workers in tertiary care hospitals in India. J. Gastroenterol. Hepatol. 23, 1710-1715 (2008).

32. Kondili LA, Ulqinaku D, Hajdini M et al. Hepatitis B virus infection in health care workers in Albania: a country still highly endemic for HBV infection. Infection 35, 94-97 (2007).

33. Abdelwahab S, Rewisha E, Hashem M et al. Risk factors for hepatitis $\mathrm{C}$ virus infection among Egyptian healthcare workers in a national liver diseases referral centre. Trans. R. Soc. Trop. Med. Hyg. 106, 98-103 (2012).

34. Olokoba AB, Salawu FK, Danburam A et al. Hepatitis $B$ virus infection amongst pregnant women in north-eastern Nigeria - a call for action. Niger. J. Clin. Pract. 14, 10-13 (2011).

35. Wurie IM, Wurie AT, Gevao SM. Seroprevalence of hepatitis B virus among middle to high socio-economic antenatal population in Sierra Leone. West Afr. J. Med. 24, 18-20 (2005).

36. Allain JP, Candotti D, Soldan K et al. The risk of hepatitis $B$ virus infection by transfusion in Kumasi, Ghana. Blood 101, 2419-2425 (2003).

37. Liaw YF, Sung JJ, Chow WC et al. Lamivudine for patients with chronic 
hepatitis B and advanced liver disease. N. Engl. J. Med. 351, 1521-1531 (2004).

38. Bruno S, Stroffolini T, Colombo M et al. Sustained virological response to interferon-alpha is associated with improved outcome in HCV-related cirrhosis: a retrospective study. Hepatology 45, 579-587 (2007).

39. Marcellin P, Gane E, Buti M et al. Regression of cirrhosis during treatment with tenofovir disoproxil fumarate for chronic hepatitis B: a 5-year open-label follow-up study. Lancet 381(9865), 468-4675 (2012).

40. Zoulim F, Locarnini S. Hepatitis B virus resistance to nucleos $(\mathrm{t})$ ide analogues. Gastroenterology 137, 1593-1608 (2009).

41. Lacombe K, Bottero J, Lemoine M, Boyd A, Girard PM. HIV/hepatitis B virus co-infection: current challenges and new strategies. J. Antimicrob. Chemother. 65, 10-17 (2010).

42. Ford N, Calmy A. Improving first-line antiretroviral therapy in resource-limited settings. Curr. Opin. HIV AIDS 5, 38-47 (2010).

43. Stewart B, Jobarteh ML, Sarge-Njie R et al. Emergence of HBV resistance to lamivudine (3TC) in HIV/HBV co-infected patients in The Gambia, west Africa. BMC Res. Notes 4 , 561 (2011).

44. Kim HN, Scott J, Cent A et al. HBV lamivudine resistance among hepatitis B and HIV coinfected patients starting lamivudine, stavudine and nevirapine in Kenya. J. Viral Hepat. 18, e447-e452 (2011).

45. Welsch C, Jesudian A, Zeuzem S, Jacobson I. New direct-acting antiviral agents for the treatment of hepatitis $\mathrm{C}$ virus infection and perspectives. Gut 61 (Suppl. 1), i36-i46 (2012).
46. Ford N, Kirby C, Singh K et al. Chronic hepatitis $\mathrm{C}$ treatment outcomes in low- and middle-income countries: a systematic review and meta-analysis. Bull World Health Organ. 90, 540-550 (2012).

47. Durier N, Nguyen C, White LJ. Treatment of hepatitis $\mathrm{C}$ as prevention: a modeling case study in Vietnam. PLoS ONE 7, e34548 (2012).

48. Sen AK. Development as Freedom. Oxford University Press, Oxford, UK (1999).

49. Kaplan W, Laing R. Essential Medicines for Europe and the World. Essential Drugs and Medicines Policy. WHO (2004).

50. Sampat BN. Academic patents and access to medicines in developing countries. Am. J. Public Health 99, 9-17 (2009).

51. Hoen E, Berger J, Calmy A, Moon S. Driving a decade of change: HIV/AIDS, patents and access to medicines for all. J. Int. AIDS Soc. 14, 15 (2011).

52. Rawls J. A Theory of Justice. Simon \& Schuster, NY, USA (1971).

53. Marseille E, Hofmann PB, Kahn JG. HIV prevention before HAART in sub-Saharan Africa. Lancet 359, 1851-1856 (2002).

54. Piot P. No time to lose. A life in pursuit of deadly viruses. WW Norton \& Company Ltd, London, UK (2012).

55. Lemoine M, Girard PM, Thursz M, Raguin G. In the shadow of HIV/AIDS: forgotten diseases in sub-Saharan Africa. Global health issues and funding agency responsibilities. J. Public Health Policy 33(4), 430-438 (2012).

56. Logie DE, Rowson M, Ndagije F. Innovations in Rwanda's health system: looking to the future. Lancet 372, 256-261 (2008).

57. Tuaillon E, Mondain AM, Meroueh F et al. Dried blood spot for hepatitis $\mathrm{C}$ virus serology and molecular testing. Hepatology 51, 752-758 (2010).

\section{Websites}

101. WHO. Hepatitis B. www.who.int/csr/disease/hepatitis/ HepatitisB_whocdscsrlyo2002_2.pdf (Accessed 11 January 2013)

102. UN Development Programme. www.hdr.undp.org/en/statistics (Accessed 12 October 2012)

103. International Agency for Research on Cancer. GLOBOCAN factsheet 2008. http://globocan.iarc.fr (Accessed 11 January 2013)

104. WHO. Prevention and control of viral hepatitis infection: framework for global action.

www.who.int/csr/disease/hepatitis/GHP_ framework.pdf

(Accessed 2 September 2012)

105. WHO. Towards universal access. www.who.int/hiv/pub/tuapr_2009_en.pdf (Accessed 2 September 2012)

106. Health Impact Fund. www.healthimpactfund.org (Accessed 11 October 2012)

107. WHO. 63rd World Health Assembly. WHA63.18: viral hepatitis (2010). http://apps.who.int/gb/ebwha/pdf_files/ WHA63/A63_15-en.pdf (Accessed 10 November 2012)

108. L'Appel de Dakar (The Dakar Appeal). www.worldhepatitisalliance.org/es/ whdinitiatives. aspx? whd $=$ whd \& iid $=136$ (Accessed 11 October 2012)

109. 2012 UNAIDS World AIDS Day Report. www.unaids.org/en/media/unaids/ contentassets/documents/epidemiology/2012/ gr2012/20121120_UNAIDS_Global_ Report_2012_en.pdf (Accessed 11 January 2012) 